
of the Creative Commons Attribution-NonCommercial-ShareAlike licence (http://creativecommons.org/licenses/by-nc-sa/4.0/), which permits noncommercial re-use, distribution, and reproduction in any medium, provided the same Creative Commons licence is included and the original work is properly cited. The written permission of Cambridge University Press must be obtained for commercial re-use.

\title{
Constraining Governments: New Indices of Vertical, Horizontal, and Diagonal Accountability
}

\author{
ANNA LÜHRMANN University of Gothenburg \\ KYLE L. MARQUARDT National Research University Higher School of Economics \\ VALERIYA MECHKOVA University of Gothenburg
}

\begin{abstract}
$A$ ccountability - constraints on a government's use of political power-is one of the cornerstones of good governance. However, conceptual stretching and a lack of reliable measures have limited cross-national research on this concept. To address this research gap, we use V-Dem data and innovative Bayesian methods to develop new indices of accountability and its subtypes: the extent to which governments are accountable to citizens (vertical accountability), other state institutions (horizontal accountability), and the media and civil society (diagonal accountability). In this article, we describe the conceptual and empirical framework underlying these indices and demonstrate their content, convergent, and construct validity. The resulting indices have unprecedented coverage (1900-present) and offer researchers and policymakers new opportunities to investigate the causes and consequences of accountability and its disaggregated subtypes. Furthermore, the methodology provides a framework for theoretically driven index construction to scholars working with cross-national panel data.
\end{abstract}

A ccountability is at the center of many socialscientific and policy debates (WBI 2005). Indeed, accountable institutions are a target

Anna Lührmann (D), Assistant Professor, Department of Political Science; and Deputy Director of the Varieties of Democracy Institute, University of Gothenburg, anna.luehrmann@v-dem.net.

Kyle L. Marquardt (D), Assistant Professor, School of Politics and Governance; and Research Fellow, International Center for the Study of Institutions and Development, National Research University Higher School of Economics, kmarquardt@hse.ru.

Valeriya Mechkova (D, Doctoral Student, Department of Political Science and the Varieties of Democracy Institute, University of Gothenburg, valeriya.mechkova@v-dem.net.

The authors contributed equally and are listed alphabetically. For their helpful comments, we thank Ryan Bakker, Ruth Carlitz, Michael Coppedge, Adam Harris, Kristen Kao, Staffan I. Lindberg, Daniel Pemstein, Juraj Medzihorsky, Simona Piattoni, Svend-Erik Skaaning, anonymous reviewers, and the editors of APSR. We also thank participants in the 2016 Development Research Conference at Stockholm University, the 2017 V-Dem May Conference, and 2017 European Consortium for Political Research General Conference. This research project was supported by the Riksbankens Jubileumsfond (Grant M13-0559:1, PI: Staffan I. Lindberg); the Knut and Alice Wallenberg Foundation (Grant 2013.0166, PI: Staffan I. Lindberg); the European Research Council (Grant 724191, PI: Staffan I. Lindberg); and internal grants from the Vice-Chancellor's office, the Dean of the College of Social Sciences, and the Department of Political Science at University of Gothenburg. We performed simulations and other computational tasks using resources provided by the Swedish National Infrastructure for Computing (SNIC) at the National Supercomputer Center in Sweden, SNIC 2016/1-382. Marquardt acknowledges the support of the HSE University Basic Research Program and funding by the Russian Academic Excellence Project '5-100.' Replication files are available at the American Political Science Review Dataverse: https:// doi.org/10.7910/DVN/TI7ORN.

Received: December 04, 2018; revised: March 23, 2020; accepted: April 08, 2020. of Sustainable Development Goal 16 (UN Resolution: A/Res/70/1). However, analyzing accountability crossnationally faces two impediments. First, the concept is "overstretched" (Lindberg 2013). Second, the only cross-national accountability index (the World Bank Voice and Accountability Index, WBGI VA) has limited temporal coverage and is conceptually inconsistent and opaque (Apaza 2009; Langbein and Knack 2010; Thomas 2010).

We present both a conceptual framework and empirical measures of accountability that address these shortcomings. We define accountability as de facto constraints on the government's use of political power through requirements for justification of its actions and potential sanctions. We further organize accountability by subtypes, using the common distinction between vertical and horizontal accountability and including a third subtype, diagonal accountability.

The advantages of our measures are fourfold. First, we use an innovative Bayesian modeling strategy to create indices for all three accountability subtypes and an overall accountability index. This strategy allows us to deal with both systematic missingness and the nested structure of the data, issues common in cross-national indices. Second, the indices have unprecedented coverage (virtually all countries from 1900-2016) and will be updated yearly. Third, they allow researchers to differentiate between subtypes of accountability.

Fourth, we demonstrate the validity of the new accountability measures by following Adcock and Collier's (2001) framework. We show content validity by demonstrating that our measures align with our specific conceptualization of accountability, and we show convergent validity by illustrating that they have theoretically expected relationships with related measures. Finally, we demonstrate 
construct validity by showing that the measures of accountability produce theoretically expected results in regression analyses, while the WBGI VA does not.

\section{EXISTING MEASURES OF ACCOUNTABILITY}

The WBGI VA is the only accountability index with worldwide coverage, from 1996 onwards. It is an aggregation of perception-based indicators from various sources (Kaufmann, Kraay, and Mastruzzi 2010), and the number of sources per observation varies between one and 19. This structure has led to criticism that the index lacks conceptual consistency and validity (Apaza 2009; Langbein and Knack 2010; Thomas 2010).

Other accountability indices are limited in either cross-national coverage or the aspect of accountability they cover. For example, Williams (2015) provides a measure of accountability and transparency that covers a limited number of countries, 1980-present. The Global Integrity Report (2011) includes a set of indicators on government oversight, electoral integrity, and anticorruption, but it covers only 33 countries in 2016. The World Bank's IDA Resource Allocation Index also provides some information on horizontal and social accountability, but only for 72 countries (IDA 2016).

Therefore, scholars have used indices of democracy - a broader concept than accountability-as proxies for accountability (Adsera, Boix, and Payne 2003; Gerring, Thacker, and Alfaro 2012; Harding and Wantchekon 2010).

\section{CONCEPTUALIZING ACCOUNTABILITY}

Accountability is a relationship between two actors, where " $\mathrm{A}$ is accountable to $\mathrm{B}$ when $\mathrm{A}$ is obliged to inform B about A's ... actions and decisions, to justify them, and to suffer punishment in the case of eventual misconduct" (Schedler, Diamond, and Plattner 1999, 17). We build on this definition by discussing three related issues: (1) to whom a government is accountable, (2) for what it is accountable, and (3) how it is held accountable.

(1) Accountability to whom? We focus on the accountability of the executive branch of the government to citizens, which is a principal-agent problem (Bovens 2007). Oversight bodies, such as the judiciary and the legislature, act simultaneously as the citizen's agents and as principals in overseeing the executive. The media and civil society have a distinct, intermediary role in this context. They have not delegated power to the government and thus are not principals in a strict sense. However, they contribute to accountability by extracting and amplifying information, helping address the information asymmetry between the government and its principals (Mechkova et al. 2019).

\footnotetext{
${ }^{1}$ Though accountability has substantial subnational variation, we leave this topic to future research.
}

(2) Accountability about what? Accountability constrains the government's use of power (Lindberg 2013), which entails both preventing illicit behavior and evaluating politicians' performance (Goetz 2008). Accountability thus helps citizens ensure that governments are responsive to their interests (WBI 2005).

(3) How is accountability enacted? Accountability has two main dimensions: answerability and enforcement (Schedler, Diamond, and Plattner 1999). The former includes the oversight of governments, while the latter involves rewarding good behavior and punishing undesired behavior (Goetz 2008). Some institutions operate on only one of these dimensions (Lindberg 2013). For example, while journalists can provide information about government misconduct, they cannot impose penalties (Bovens 2007). In contrast, institutions of vertical accountability mainly concern enforcement.

The preceding discussion leads us to define accountability as de facto constraints on the government's use of political power through requirements for justification of its actions and potential sanctions by both citizens and oversight institutions.

This conceptualization of accountability is distinct from classic descriptions of democracy, which focus on how citizens use elections to hold politicians accountable (Schmitter and Karl 1991). There is substantial variation in the degree to which accountability actors other than voters constrain governments; such institutions can also exist in nondemocratic states (Lindberg 2013).

\section{OPERATIONALIZATION OF ACCOUNTABILITY}

Since multiple actors enact accountability, we organize accountability into subtypes based on the spatial direction between its actors (Lindberg 2013). Specifically, we operationalize accountability as three distinct subtypes: vertical, horizontal, and diagonal. Vertical accountability is a relationship between unequals (the government and citizens), while horizontal accountability is a relationship between more or less equal institutions (different branches of government; O'Donnell 1998). Diagonal accountability represents the extent to which actors outside of formal political institutions (e.g., the media and civil society) hold a government accountable. We follow Goetz and Jenkins (2001) in describing this form of accountability as "diagonal," as opposed to "social" (Malena and Forster 2004), because its success ultimately depends on other accountability institutions (Mainwaring and Welna 2003). Figure 1 presents these relationships.

\section{Aggregation Strategy}

Measuring accountability necessitates a strategy that diverges from standard latent variable techniques (Bernhard et al. 2017; Pemstein, Meserve, and Melton 2010; Treier and Jackman 2008). Specifically, we deal 


\section{FIGURE 1. Relationship of Accountability Subtypes}

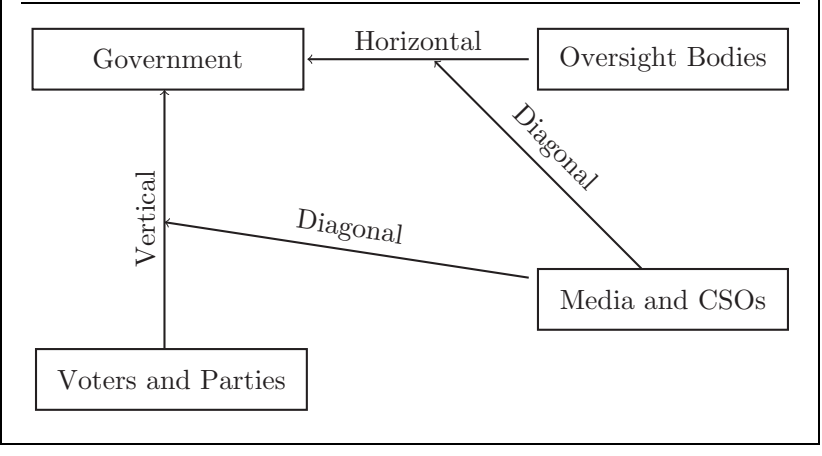

directly with two issues common to indices that use cross-national panel data.

First, latent concepts such as accountability have a hierarchical structure: accountability is manifested in its subtypes, which are themselves latent concepts manifested in a combination of subconcepts (e.g., "civil society") and manifest variables (e.g., "elected executive"). We explicitly model this hierarchical structure, thereby allowing it to inform our latent concept estimates. Because such hierarchical latent variable modeling strategies inherently involve prior information, we employ a Bayesian estimation approach. ${ }^{2}$

Second, data regarding some de facto phenomena are systematically missing because the institutions they capture do not exist. For example, free and fair elections do not exist in countries without elections. Since the existence of these institutions itself is important to accountability, we use structural modeling techniques to condition the relationship between de facto indicators and accountability on the presence of the institutions.

Because our conceptualization of accountability relies on the de facto activity of political institutions, we use indicators from the V-Dem dataset to construct our indices (Coppedge et al. 2017). V-Dem uses experts to code such difficult-to-observe activities, which the project aggregates using an item-response theory model (Pemstein et al. 2015).

\section{Vertical Accountability}

Vertical accountability (Figure 2) regards the ability of a state's population to hold its government accountable through elections and political parties (Schedler, Diamond, and Plattner 1999). Electoral accountability includes (1) election quality, (2) enfranchised population share, and (3) whether the chief executive is subject to direct or indirect elections. To measure election quality, we take into account (a) whether there are elections and (b) if so, the degree to which elections reflect the people's will. Specifically, we model the quality of elections as a function of the presence of

\footnotetext{
${ }^{2}$ We use rjags and runjags (Denwood 2016; Plummer 2003) to estimate the models. Appendix A details the aggregation strategy and robustness checks.
}

elections, assuming that a polity without elections has a lower level of vertical accountability than a polity with elections. We measure election quality by using seven variables that are directly related to this concept. ${ }^{3}$

We load the remaining two election-related variables (suffrage and elected executive) directly into the vertical accountability index. This strategy accords with our a priori belief that each of these electoral aspects is equally important to vertical accountability.

Finally, since political parties can incentivize accountability by ensuring that politicians follow a political program and abstain from activities that hurt the party's reputation (Gehlbach and Keefer 2011; Svolik 2012), we incorporate party quality into vertical accountability as a latent concept manifested in three relevant indicators.

\section{Horizontal Accountability}

Horizontal accountability (Figure 3) represents the extent to which state institutions hold the executive branch of the government accountable. This form of accountability requires the existence of institutions-legislative and judicial branches, and other oversight agencies-that can demand information and punish improper behavior (O’Donnell 1998; Rose-Ackerman 1996).

We incorporate judicial oversight into horizontal accountability as a nested latent variable with four manifest variables, using the same strategy as for party quality in vertical accountability. To measure the ability of a legislature to hold the government accountable, we incorporate two manifest variables capturing this concept. Since polities without legislatures are unable to implement this form of accountability, we model the degree to which the legislature holds the executive branch accountable as a function of the existence of a legislature.

We directly load two additional manifest variables into the model: executive self-restraint and the degree to which state bodies (e.g., an ombudsman) investigate an executive's activities.

\section{Diagonal Accountability}

Diagonal accountability (Figure 4) reflects the contribution of non-state actors to accountability. Civil society organizations, an independent media, and engaged citizens can use a broad range of actions to provide and amplify information about the government, thereby holding it accountable (Grimes 2013; Malena and Forster 2004). For example, media reporting can help principals such as voters and legislatures make informed choices (Voltmer 2010), and civil society organizations can directly pressure the government to change a specific policy (Peruzzotti and Smulovitz 2006).

We model this form of accountability as being manifested in six variables on media freedom, three variables regarding civil society characteristics (the V-Dem civil society core index; Bernhard et al. 2017), four variables of freedom of expression, and one

\footnotetext{
${ }^{3}$ Indicator description in Appendix B.
} 


\section{FIGURE 2. Vertical Accountability}

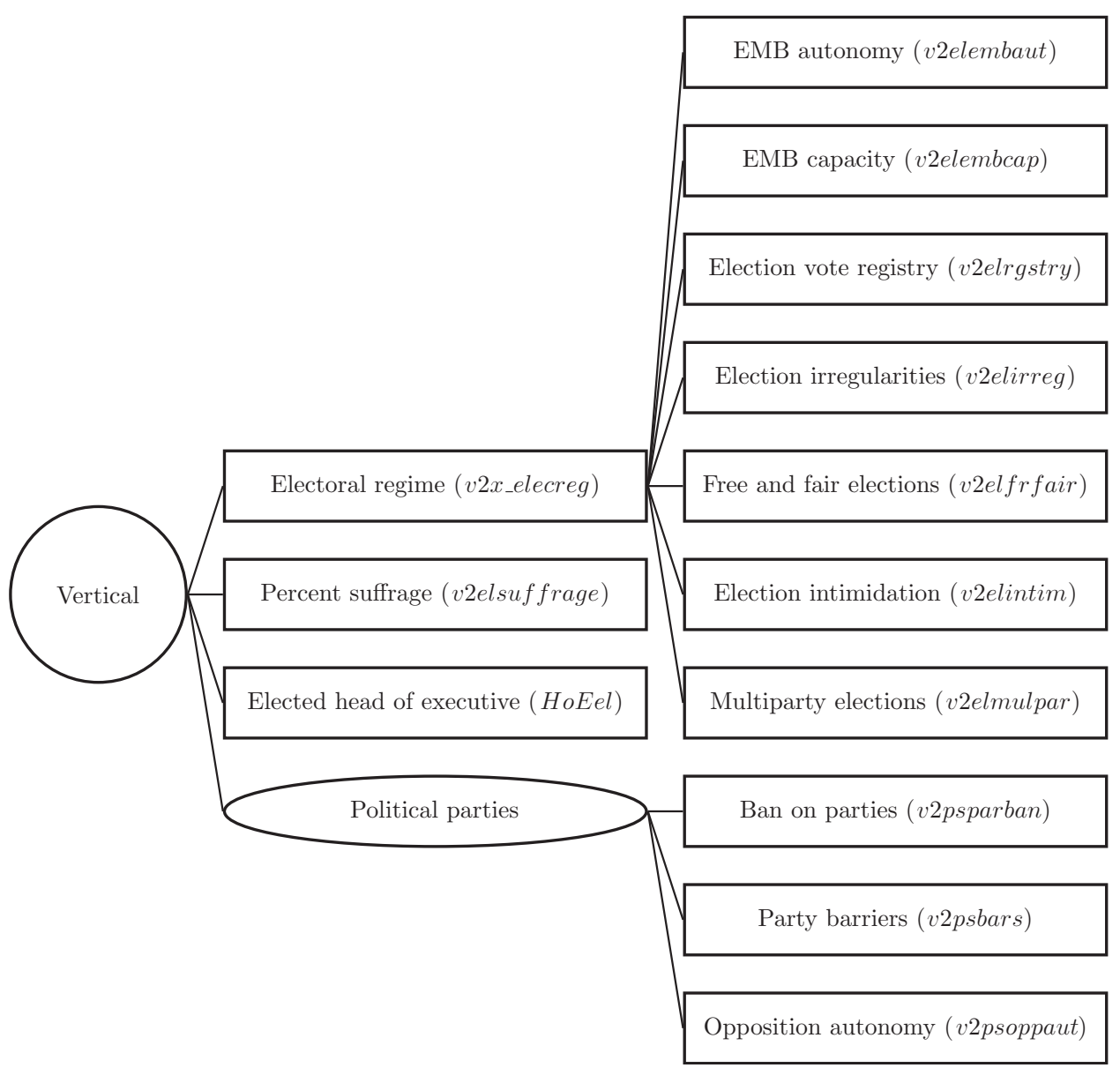

Note: Rectangles represent manifest variables; circles latent variables. Italics represent V-Dem codes.

\section{FIGURE 3. Horizontal Accountability}

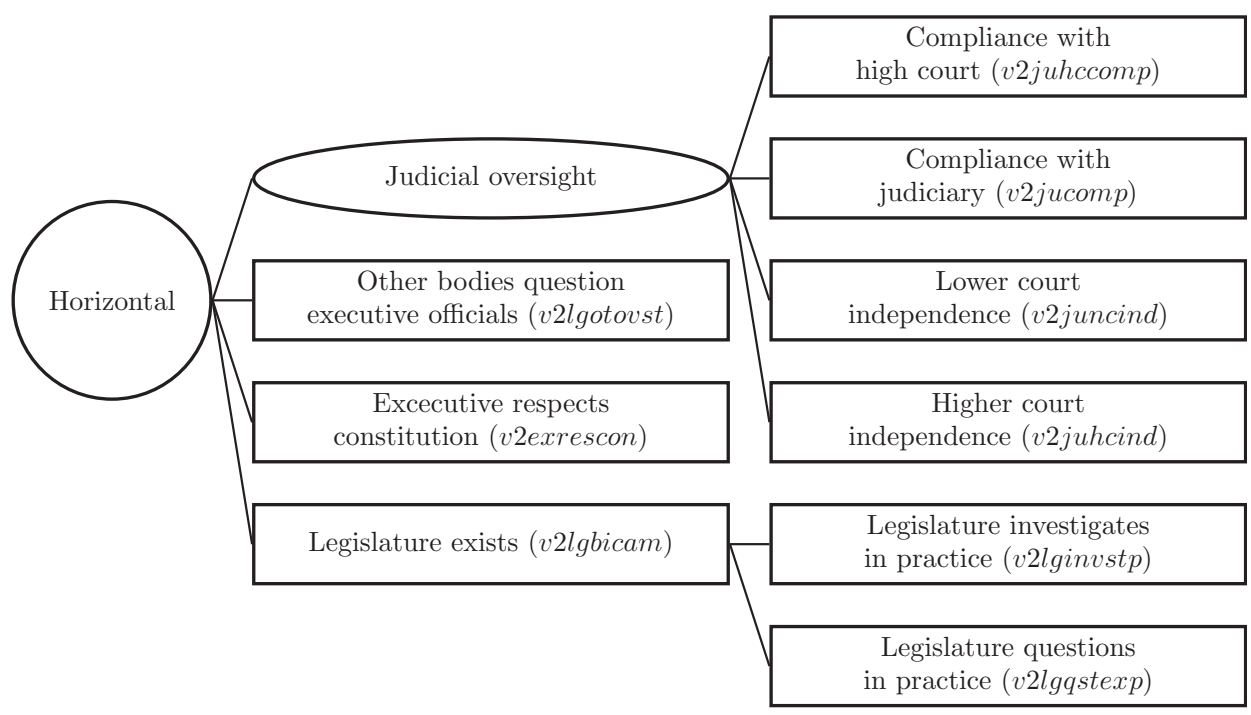

Note: Rectangles represent manifest variables; circles latent variables. Italics represent V-Dem codes. 


\section{FIGURE 4. Diagonal Accountability}

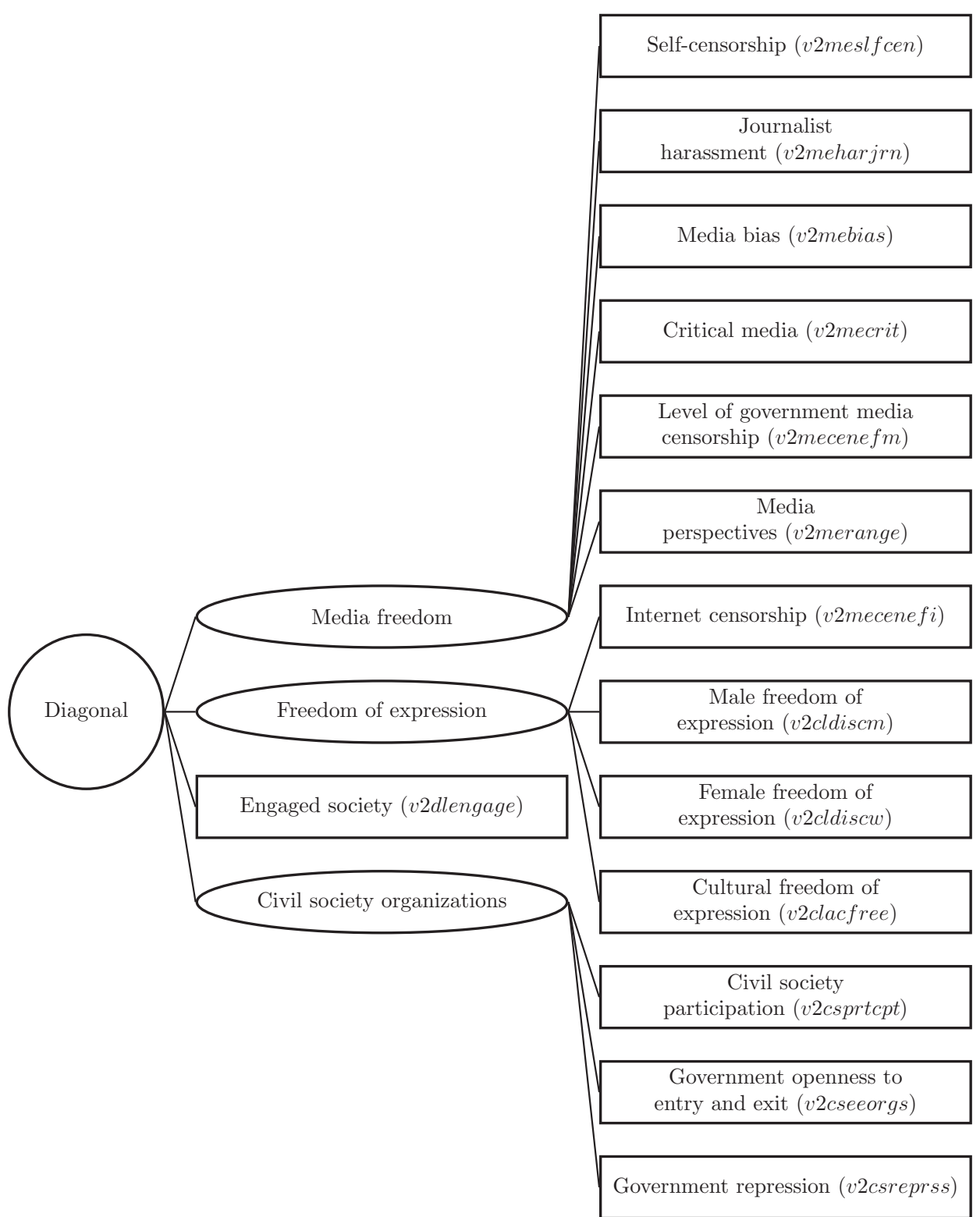

Note: Rectangles represent manifest variables; circles latent variables. Italics represent V-Dem codes.

variable related to citizen engagement with politics. We model all concepts except for citizen engagement as hierarchically nested latent variables.

\section{Accountability}

We create a composite measure of accountability using a hierarchical latent variable model, clustering indicators and concepts by type of accountability (Figure 5). This strategy assumes that accountability is a function of all of the indicators that were described in the previous sections, though our conceptualization of accountability subtypes structures this relationship.
This model assumes that the different subtypes of accountability are largely complementary. However, in some cases principals disagree and thereby weaken each other, instead of constraining the government (Voorn, van Genugten, and van Thiel 2019). Since our data reflect de facto institutions, weakness in any subtype will result in lower scores, regardless of the source of the weakness-be it conflict between accountability institutions or a lack of independence or capacity (Appendix E.2).

\section{VALIDATION}

Since the true values of any latent concept are unknown (McMann et al. 2016), we validate our indices by using 
content, convergent, and construct validation procedures (Adcock and Collier 2001).

\section{Content Validation}

Content validation concerns the alignment of a measure with its underlying concept (Adcock and Collier 2001). In addition to the detailed operationalization and conceptualization in previous sections, we emphasize two points to this end. First, the V-Dem data that we use closely match our theoretical framework, representing a major step forward from earlier indices of accountability. Second, our measures capture empirically important variation in

\section{FIGURE 5. Accountability}

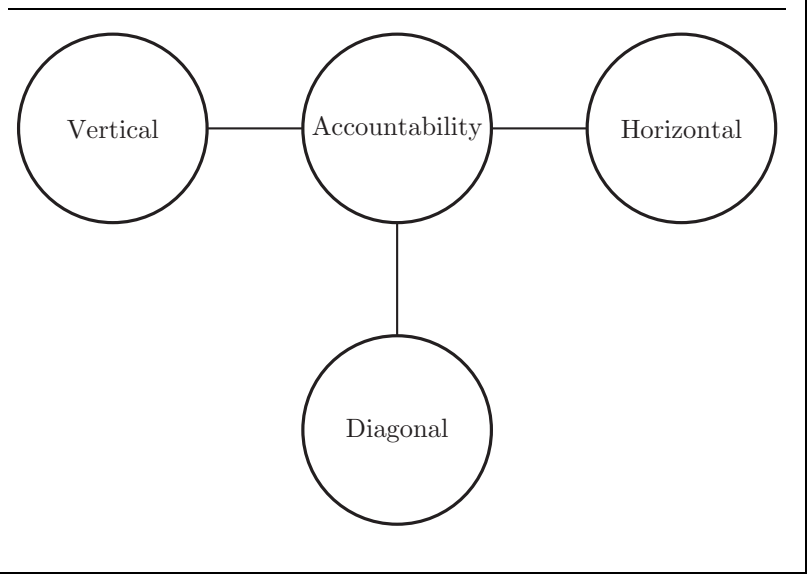

accountability at both the cross-national and country levels over time.

\section{Global Development of Accountability over Time}

Our indices cover 177 polities from 1900 to 2016 (descriptive statistics in Appendix D). Figure 6 illustrates the cross-national average level of different forms of accountability over time, which tracks the waves of democratization and concomitant social and economic changes (Huntington 1993).

While their broad trends are similar, the subindices of accountability evolve differently over time. For example, the global mean of horizontal accountability begins a period of largely upward movement only in the late 1980s, after the fall of Communist regimes in Eastern Europe. However, this increase is less pronounced than the changes in diagonal and vertical accountability are, since horizontal accountability mechanisms take more time to develop after a political transition (Mechkova, Lührmann, and Lindberg 2019).

Appendix F.1 presents additional analyses of accountability trends in the BRICS countries and a liberal democracy (France). These cases demonstrate how the three subtypes of accountability evolved in different patterns in individual countries. A case in point is the transition from apartheid in South Africa. Horizontal accountability began improving in 1984, reflecting attempts to reform from above. However, diagonal accountability only began increasing in 1990 after the release of political prisoners and negotiations for a new constitution. Higher scores for vertical accountability were not achieved until after the 1994 elections.

FIGURE 6. Accountability Indices Global Mean 1900-2016

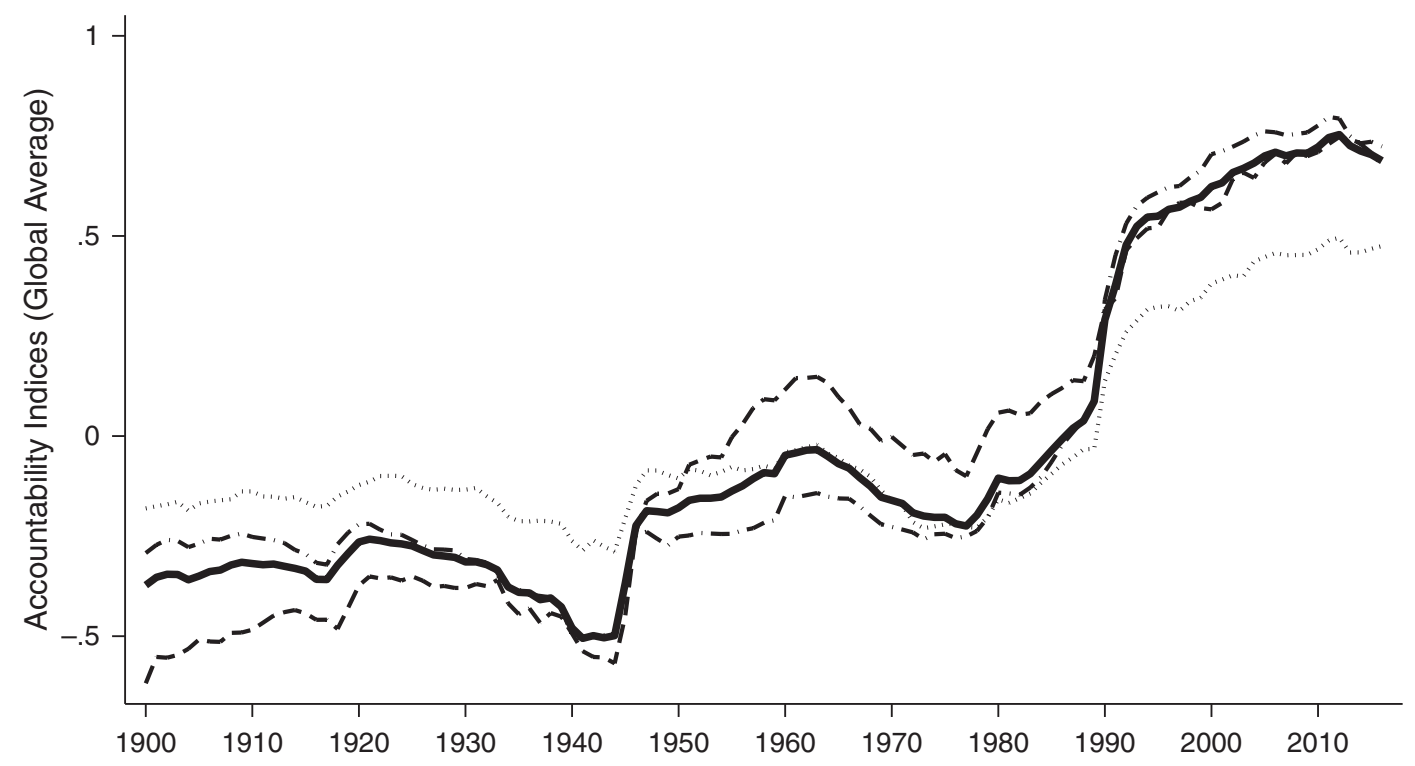

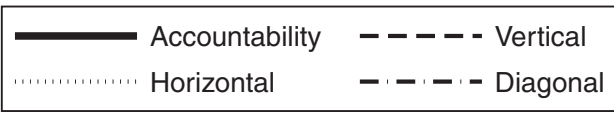




\section{FIGURE 7. Relationship Between Accountability Subindices}

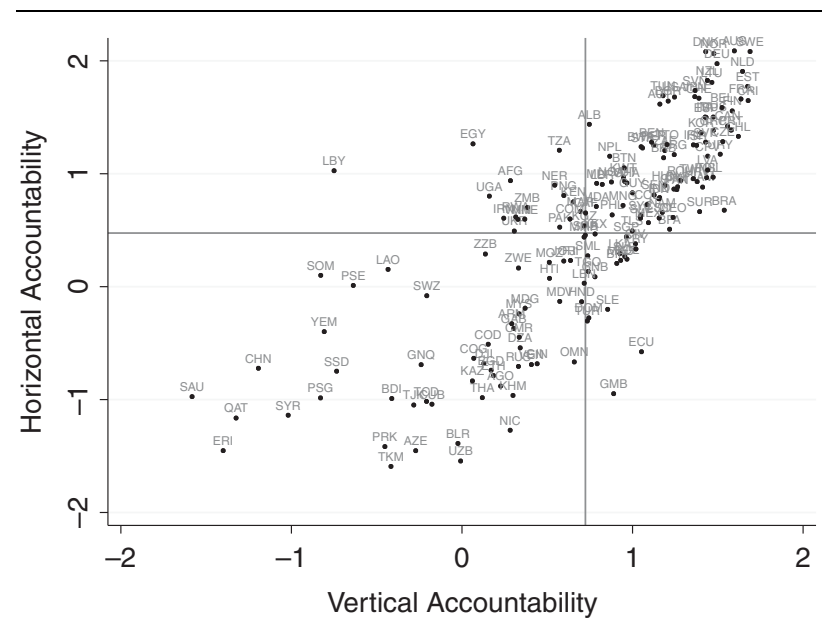

(a) VERTICAL and HORIZONTAL ACCOUNTABILITY

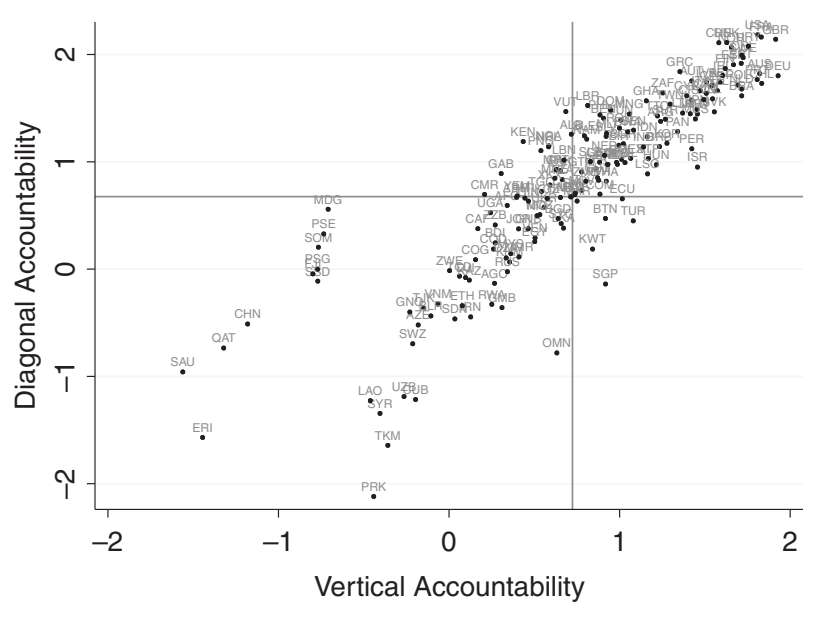

(b) VERTICAL and DIAGONAL ACCOUNTABILITY

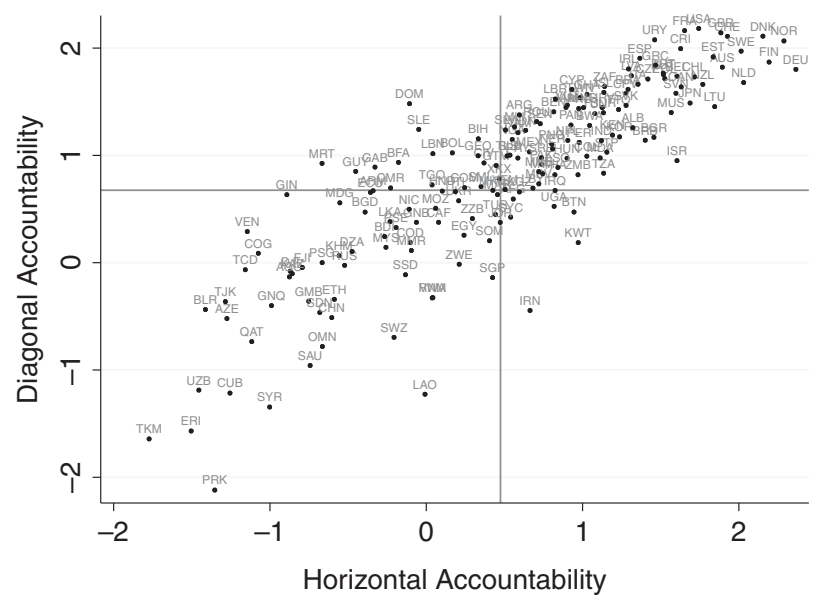

(c) HORIZONTAL and DIAGONAL ACCOUNTABILITY

\section{Case-level Variation in Accountability Subtypes}

Figure 7 illustrates the relationship of accountability subtypes across countries in 2016. The gray lines show the 2016 world average. Countries with high levels on a given index tend to have high values across indices; variation across subtypes is more widespread among countries with lower levels of accountability. For instance, regimes with highly flawed elections or no elected executives have low levels of vertical accountability (e.g., Eritrea and China; Figure 7a). However, these countries exhibit varying levels of horizontal and diagonal accountability. For example, China has a more active civil society and a stronger rule of law than Eritrea does, so it scores slightly higher on these dimensions (Figure 7a and 7c).

Bangladesh and Iran are also both on the lower end of the accountability spectrum. However, horizontal accountability scores for Iran are relatively high, reflecting its comparatively strong oversight bodies (Figure 7a). Conversely, Bangladesh has a low horizontal accountability score, whereas its level of diagonal accountability is close to world average due to its relatively powerful civil society (Figure $7 \mathrm{~b}$ ).

\section{Convergent Validation}

Convergent validation strategies assess correlation with other indices that measure similar concepts (Adcock and Collier 2001). Here we do so by analyzing the relationship of our accountability indices to (1) each other, (2) other accountability indices, and (3) democracy indices (detailed analyses in Appendix F.2).

Since we conceptualize all three accountability subtypes as part of a larger concept (accountability), they should strongly correlate with each other. Since diagonal accountability bridges and enhances horizontal and vertical accountability, it should correlate more strongly with these two subtypes of accountability than they do with each other. Indeed, the correlation between horizontal and vertical accountability is the weakest (0.72), while the correlations between diagonal and both vertical and horizontal accountability are relatively high (0.83 and 0.82 , respectively). Diagonal 
FIGURE 8. Relationship Between Accountability and Infant Mortality

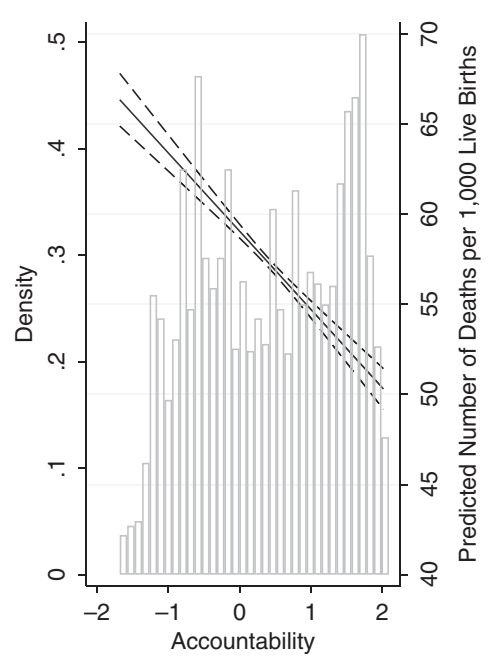

(a) MODEL 1

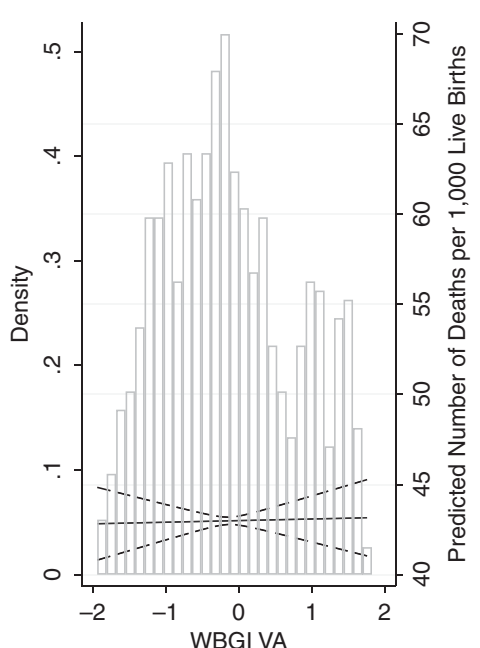

(b) MODEL 2
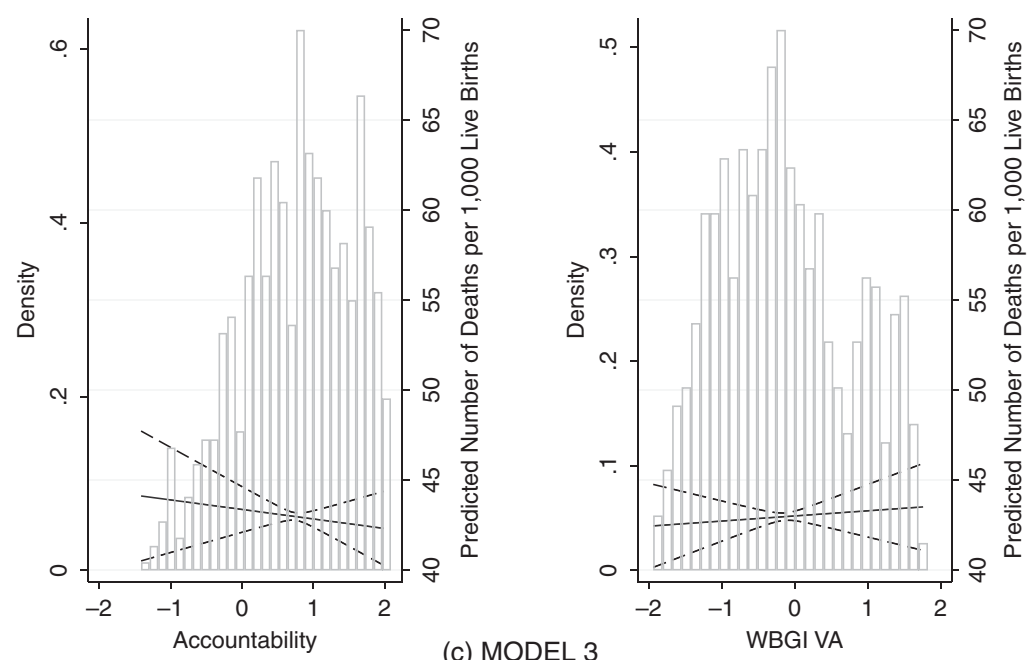

(c) MODEL 3
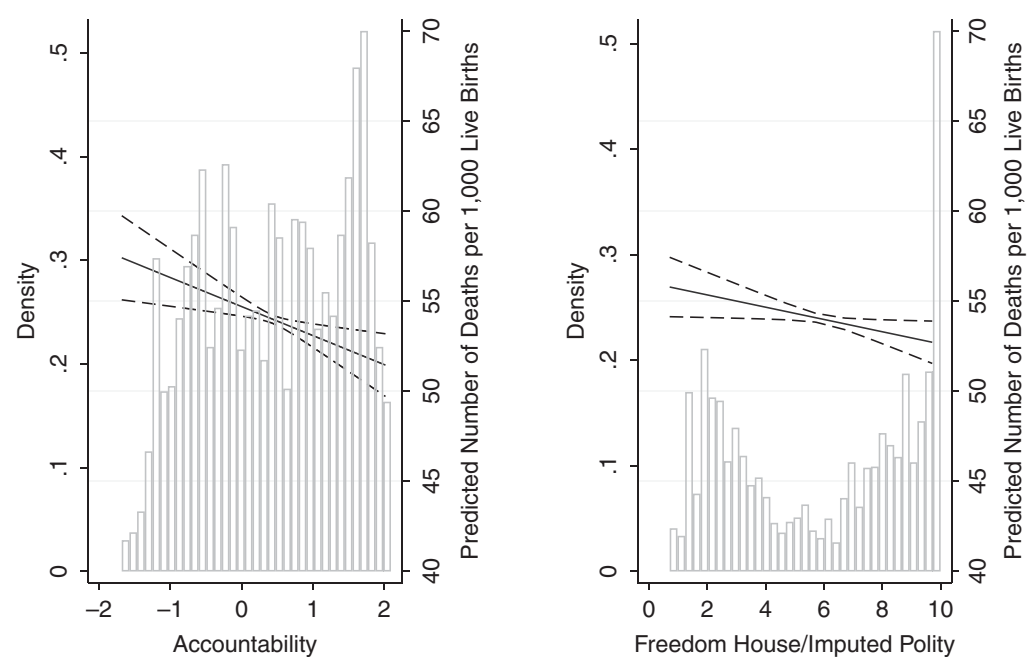

(d) MODEL 4 
accountability also has a stronger correlation with the overall accountability index (0.97) than does either horizontal or vertical accountability (0.88 and 0.91 , respectively). This correlation structure analytically follows from diagonal accountability's strong correlation with the other subtypes.

We also expect a strong correlation between our indices and existing measures of accountability. Indeed, the WBGI VA correlates strongly with our accountability measures. Its highest correlation is with the overall accountability index (0.92), and the lowest is with horizontal accountability (0.85). This finding enhances the convergent validity of our indices because the WBGI VA includes measures of election quality, media freedom, and civil and political rights, which overall accountability captures but horizontal accountability does not.

Finally, we expect a high correlation between measures of accountability and democracy because they are closely-linked concepts. However, different subtypes of accountability should correlate more highly with some measures of democracy than with others, in line with the particular concepts these measures estimate. For example, the Freedom House/Polity combined measure includes concepts related to vertical and diagonal accountability and thus correlates more strongly with these subtypes ( 0.88 and 0.90 , respectively) than with horizontal accountability (0.82).

\section{Construct Validation}

Construct validation involves demonstrating that a new measure yields theoretically expected results (Adcock and Collier 2001). Since many scholars argue that accountability improves human development (Gerring, Thacker, and Alfaro 2012; Miller 2015; WBI 2005), we use a key human development outcome (infant mortality) for this validation. We only present results for the accountability index; subtype analyses yield similar results (Appendix F.3).

\section{Data and Analysis}

We use data from Miller (2015), who proxies accountability with categorical indicators of regime type. He finds that democracies achieve better development outcomes than autocracies do and that, among autocracies, countries with elections perform better. We largely replicate his analysis, estimating an ordinary least squares model with year- and country-fixed effects and using the same controls. Our models diverge from Miller's in that we (1) substitute measures of accountability and democracy for his categorical indicators and (2) add a measure of corruption in the model because corruption can hinder human development (Holmberg and Rothstein 2011).

Figure 8 presents the estimated relationships between accountability and infant mortality (full results in Appendix F.3). Figure 8a shows the predicted number of deaths per 1,000 births at different levels of accountability. The results indicate that accountability has the theoretically expected strong negative correlation with infant mortality. In contrast, Figure $8 \mathrm{~b}$ illustrates the results from a model that instead includes the WBGI VA index; WBGI VA evinces a weak positive correlation with infant mortality, the opposite of theoretical expectations. Figure $8 \mathrm{c}$ presents the estimated relationship between infant mortality and both our accountability index (left) and the WBGI VA (right) from a model including both variables. Given the high correlation between the two indices and low coverage of the WBGI VA, the magnitude of the relationship between the accountability index and infant mortality is much diminished; however, its coefficient is in the expected negative direction.

Figure 8d presents the results from a regression analysis that includes both our accountability index and Freedom House/Polity combined measure. Both democracy and accountability show a negative and substantively strong relationship with infant mortality, indicating that our conceptualization of accountability is both meaningful and different from democracy.

\section{CONCLUSION}

Accountability is essential to effective governance. However, researchers and policymakers lack valid cross-national measures of this concept. The indices we present in this paper fill this gap, using an innovative measurement strategy to provide conceptually rigorous and empirically valid measures of accountability. Moreover, our hierarchical operationalization of accountability will allow researchers to work at both disaggregated and aggregate levels. For instance, scholars can use the subtype indices to test Dahl's (1971) assumption that institutional stability benefits if horizontal accountability evolves before vertical accountability. Researchers can also use the overall accountability index to assess accountability's relationship with vital outcomes such as democratic backsliding and corruption.

\section{SUPPLEMENTARY MATERIALS}

To view supplementary material for this article, please visit http://dx.doi.org/10.1017/S0003055420000222.

Replication files are available at the American Political Science Review Dataverse: https://doi.org/10.7910/ DVN/TI7ORN.

\section{REFERENCES}

Adcock, Robert, and David Collier. 2001. "Measurement Validity: A Shared Standard for Qualitative and Quantitative Research." American Political Science Review 95 (3): 529-46.

Adsera, Alicia, Carles Boix, and Mark Payne. 2003. "Are You Being Served? Political Accountability and Quality of Government." The Journal of Law, Economics, and Organization 19 (2): 445-90.

Apaza, Carmen. 2009. "Measuring Governance and Corruption Through the Worldwide Governance Indicators: Critiques, Responses, and Ongoing Scholarly Discussion." PS: Political Science \& Politics 42 (1): 139-43. 
Bernhard, Michael, Dong-Joon Jung, Eitan Tzelgov, Michael Coppedge, and Staffan I. Lindberg. 2017. "Making Embedded Knowledge Transparent: How the V-Dem Dataset Opens New Vistas in Civil Society Research." Perspectives on Politics 15 (2): 342-60.

Bovens, Mark. 2007. "Analysing and Assessing Accountability: A Conceptual Framework.” European Law Journal 13 (4): 447-68.

Coppedge, Michael, John Gerring, Staffan I. Lindberg, Svend-Erik Skaaning, Jan Teorell, David Altman, Michael Bernhard, et al. 2017. V-Dem [Country-Year/Country-Date] Dataset v7.1 [computer file]. Gothenburg, Sweden: V-Dem Institute, University of Gothenburg, Varieties of Democracy (V-Dem) Project.

Dahl, Robert. 1971. Polyarchy: Participation and Opposition. New Haven, CT: Yale University Press.

Denwood, Matthew. 2016. "runjags: An R Package Providing Interface Utilities, Model Templates, Parallel Computing Methods and Additional Distributions for MCMC Models In JAGS." Journal of Statistical Software 71 (9): 1-25.

Gehlbach, Scott, and Philip Keefer. 2011. "Investment without Democracy: Ruling-Party Institutionalization and Credible Commitment in Autocracies." Journal of Comparative Economics 39 (2): 123-39.

Gerring, John, Strom Thacker, and Rodrigo Alfaro. 2012. "Democracy and Human Development." The Journal of Politics 74 (1): 1-17.

Global Integrity. 2011. Global Integrity Report 2011. Methodology White Paper.

Goetz, Anne Marie. 2008. Who Answers to Women? Gender and Accountability. New York: United Nations Development Fund for Women.

Goetz, Anne Marie, and Rob Jenkins. 2001. "Hybrid Forms of Accountability: Citizen Engagement in Institutions of PublicSector Oversight in India." Public Management Review 3 (3): 363-83.

Grimes, Marcia. 2013. "The Contingencies of Societal Accountability: Examining the Link between Civil Society and Good Government." Studies in Comparative International Development 48 (4): 380-402.

Harding, Robin, and Leonard Wantchekon. 2010. "The Political Economy of Human Development." Human Development Research Paper 29.

Holmberg, Sören, and Bo Rothstein. 2011. "Dying of Corruption." Health Economics, Policy and Law 6 (4): 529-47.

Huntington, Samuel. 1993. The Third Wave: Democratization in the Late Twentieth Century. Vol. 4: Norman, OK: University of Oklahoma Press.

International Development Association (IDA). 2016. IDA Resource Allocation Index. World Bank Group.

Kaufmann, Daniel, Aart Kraay, and Massimo Mastruzzi. 2010. "Response to 'What Do the Worldwide Governance Indicators Measure?"' The European Journal of Development Research 22 (1): 55-8.

Langbein, Laura, and Stephen Knack. 2010. "The Worldwide Governance Indicators: Six, One, or None?" The Journal of Development Studies 46 (2): 350-70.

Lindberg, Staffan. 2013. "Mapping Accountability: Core Concept and Subtypes." International Review of Administrative Sciences 79 (2): 202-26.
Mainwaring, Scott, and Christopher Welna. 2003. Democratic Accountability in Latin America. Oxford: Oxford University Press.

Malena, Carmen, and Reiner Forster. 2004. "Social Accountability: An Introduction to the Concept and Emerging Practice." World Bank Working Paper No. 31042.

McMann, Kelly, Daniel Pemstein, Brigitte Seim, Jan Teorell, and Staffan I. Lindberg. 2016. "Strategies of Validation: Assessing the Varieties of Democracy Corruption Data." V-Dem Institute Working Paper No. 23.

Mechkova, Valeriya, Anna Lührmann, and Staffan Lindberg. 2019. "The Accountability Sequence: From De-Jure to De-Facto Constraints on Governments." Studies in Comparative International Development 54(1): 40-70.

Miller, Michael K. 2015. "Electoral Authoritarianism and Human Development." Comparative Political Studies 48 (12): 1526-62.

O'Donnell, Guillermo A. 1998. "Horizontal Accountability in New Democracies." Journal of Democracy 9 (3): 112-26.

Pemstein, Daniel, Kyle L. Marquardt, Eitan Tzelgov, Yi-ting Wang, and Farhad Miri. 2015. "The V-Dem Measurement Model: Latent Variable Analysis for Cross-national and Crosstemporal Expert-coded Data." V-Dem Institute Working Paper No. 21.

Pemstein, Daniel, Stephen Meserve, and James Melton. 2010. "Democratic Compromise: A Latent Variable Analysis of Ten Measures of Regime Type." Political Analysis 18 (4): 426-49.

Peruzzotti, Enrique, and Smulovitz Catalina, eds. 2006. Enforcing the Rule of Law: Social Accountability in the New Latin American Democracies. Pittsburgh, PA: University of Pittsburgh Press.

Plummer, Martyn. 2003. "JAGS: A Program for Analysis of Bayesian Graphical Models Using Gibbs Sampling." In Proceedings of the 3rd International Workshop on Distributed Statistical Computing. Vienna, Austria: DSC, 1-8.

Rose-Ackerman, Susan. 1996. "Democracy and 'Grand' Corruption.” International Social Science Journal 48 (149): 365-80.

Schedler, Andreas, Larry Diamond, and Marc Plattner. 1999. The Self-restraining State: Power and Accountability in New Democracies. Boulder, CO: Lynne Rienner Publishers.

Schmitter, Philippe, and Terry Lynn Karl. 1991. "What Democracy Is ... and Is Not." Journal of Democracy 2 (3): 75-88.

Svolik, Milan. 2012. The Politics of Authoritarian Rule. Cambridge MA: Cambridge University Press.

Thomas, Melissa. 2010. "What Do the Worldwide Governance Indicators Measure?" The European Journal of Development Research 22 (1): 31-54.

Treier, Shawn, and Simon Jackman. 2008. "Democracy as a Latent Variable." American Journal of Political Science 52 (1): 201-17.

Voltmer, Katrin. 2010. "The Media, Government Accountability, and Citizen Engagement." In Public Sentinel: News Media and Governance Reform, ed. Pippa Norris. World Bank, 137-59.

Voorn, Bart, Marieke van Genugten, and Sandra van Thiel. 2019. "Multiple Principals, Multiple Problems: Implications for Effective Governance and a Research Agenda for Joint Service Delivery." Public Administration 97: 671-85.

World Bank Institute (WBI). 2005. "Social Accountability in the Public Sector.” World Bank Institute Working Paper No. 33641.

Williams, Andrew. 2015. "A Global Index of Information Transparency and Accountability." Journal of Comparative Economics 43: 804-24. 